\title{
Viewpoints of Dental Practitioners Regarding Choice of Root Canal Sealers in Nepal
}

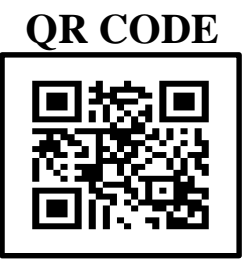

\section{MANOJ KUMAR UPADHAYAY'1, KRISHAN KUMAR TYAGI², RAJBIR KAUR KHANGURA³}

INTRODUCTION: Apical and periapical repair is one of the ultimate goal of endodontic therapy. Main objective should be the formation of a fluid tight seal at the apical foramen, which provides a suitable environment i.e. biological condition for healing of the periapical tissue. For this many different materials are being used in root canal filling nowadays.

A

AIM: The aim of this study is to assess the knowledge of root canal sealers among 130 dental practitioners in Nepal.

MATERIALS AND METHOD: The self-administered questionnaire was distributed to 130 dental practitioners in Nepal during the month of May 2017.

RESULTS: Through this study it was observed that the choice of sealers is different for every dental practitioner. All of the study participants have given multiple responses, but it was seen that AH plus followed by ZOE was the most commonly used root canal sealers.

CONCLUSION: One of the major objectives in root canal treatment is the three dimensional sealing of root canal space and it is important to have a root sealer that is commonly used with maximum results as seen with AH plus and ZOE.

KEYWORDS: Dental Practitioners, Root Canal Sealer, Treatment

\section{INTRODUCTION}

Among the comprehensive quality dental care endodontic treatment plays an essential part. There has introduction of many new instruments, materials, and techniques in the field of contemporary endodontics. There were higher success rates of more than $90 \%$ which were shown by many of the controlled studies in the root canal treatment. ${ }^{1,2}$ In the success of endodontic treatment root canal sealers play a fundamental role.

They provide a seal that is impenetrable to bacteria and other microorganisms by filling minor spaces and irregularities between the corefilling material and wall of the root canal. Their function is to fill the discrepancies between the core material and the root canal wall, as well as between the gutta-percha cones in order to create a consistent mass that completely obturates the canal. It is also of importance to note that the thickness of the endodontic sealer plays affects the quality of the root canal filling. ${ }^{1,3}$
Formation of a bacterial tight seal is the main aim of a root filling so that we can minimize or reduce the risks of infection or re-infection in the root canal which further prevents the pathologies like periradicular pathosis. $3,4,5$

No available material and/or technique is capable of producing a complete seal of the root canal entirely. Therefore, evidence suggests that root canal filling materials should be manufactured in such a way that it provides better capacity to prevent bacterial ingress over a long period of time. To achieve the success of root canal treatment, the sealers should have the properties of adhesiveness, antimicrobial efficacy, biocompatibility, dimensional stability and insolubility to dental tissue fluids, and also have a sufficient flow rate, which leads to maintenance of a three-dimensional seal of the root canal. ${ }^{1,6,7}$

The commercially available root canal sealers can be divided into Zinc-Oxide Eugenol (ZOE) based 
sealers, calcium-hydroxide $(\mathrm{CH})$ based sealers, glass ionomer (GIC) based sealers, MTA-based sealers, resin based sealers, silicone and solvent based sealers. ${ }^{2,3,8}$

It is important that the dental practitioners must have in-depth knowledge regarding the various root canal sealers to be able to carry out the root canal therapy in an effective and efficient manner.

Thus, the present study was conducted with aim to investigate the Dental Practitioners' point of view regarding root canal sealers, identifying the basis on which the choice is made, advantages as well as disadvantages of various sealers and how the information necessary for the choice is acquired.

\section{METHODOLOGY}

A questionnaire based cross-sectional survey was carried out among the 130 dental practitioners working as academicians or clinician or both in Nepal. Dental practitioners working in different clinics and colleges were randomly chosen to take part in this survey and this study was conducted during the month of May 2017.

Ethical approval was obtained from the institutional review board and participation in the study was voluntary and confidentiality of data was maintained. The questionnaire used in the study consisted of questions regarding various types of root canal sealers, their uses, advantages and disadvantages. One open ended question was also designed so as to facilitate the dentists to express their viewpoints on the mentioned determinants.

The questionnaire was pretested on 25 dentists who comprised $19 \%$ of the study sample for reliability and validity. Reliability of the questionnaire was assessed using Test-Retest and internal consistency of the questionnaire was ascertained by Chronbachs-Alpha $(\alpha)$. Construct validity of the questionnaire was assessed using spearman's correlation coefficient between individual parameter/construct and overall score of the construct.

A questionnaire with a cover letter were distributed to those who were ready to participate. The questionnaire was self- administered after explaining the study design to all of them who consented to participate in the study. They were requested to complete the questionnaire within a week and were reminded once before the deadline.

The data were collected and descriptive statistical analysis was done using statistical package for social sciences (SPSS) (Version 22.0; SPSS Inc, Chicago, IL). Inferential statistics to find out differences in choice of root sealer, if any was done by the application of ANOVA.

\section{RESULTS}

The questionnaire based study was carried out among the 130 dentists regarding the various types of root canal sealers, their uses, advantages and disadvantages. Reliability measured through TestRetest showed measured kappa (k) of 0.86 and weighted kappa (k) of o.9. Construct validity was assured using spearman correlation coefficient $(\mathrm{p}<0.001)$.

A total of 112 dentists completed the questionnaire, generating the response rate of 86 $\%$. The study sample comprised of $34.8 \%$ males and $65.2 \%$ females. Demographic characteristics such as years of teaching/practicing experience and career perspective of dental practitioners are summarized in Table 1.

Table 2 present the views of all the dental practitioners who responded to the questionnaire and among 112, majority of them were using the $\mathrm{AH}$ plus sealer and the difference was found to be statistically significant.

\section{DISCUSSION}

The role of root canal sealers is to completely obturate the root canal; therefore adhesion, solubility and leakage are of prime concern to a dental practitioner. Accordingly, sealers should not be soluble or easily disintegrate in contact with oral fluids. ${ }^{1,9}$

In our work it has been found that the sealer of choice among the dental practitioners was $\mathrm{AH}$ plus followed by ZOE whereas dental practitioners chose ZOE based sealers to be the commonly used sealer as per Ravikumar $C$ et al. ${ }^{4}$ This might be due to the reason that $\mathrm{AH}$ Plus has got excellent biological properties. In another study based on 
evaluation of the periapical repair ability of root canal sealers, the silicone-based Roeko seal and the resin based AH Plus has shown good results. ${ }^{7,8}$

Many of the other studies have also shown that Zinc oxide and eugenol-based sealers are used worldwide. The sealers with the best antibacterial activity were found to be ZOE based sealers followed by resin and calcium hydroxide based sealers by some authors, whereas others reported that resin based sealers are more potent than zinc oxide eugenol based, followed by calcium hydroxide based sealers..$^{7-9}$

Mixed response has been found regarding the usage of sealers among them as many of the dental practitioners use the Resilion followed by Metapex. Some of them are using the Intrafill and AR plus. But very few of them are into the use of Ketac-Endo. The GIC based sealers are soluble and disintegrate easily, thus favouring clinical success to a limited extent.

The resin based sealers were choice of sealers for vital and non-vital teeth. It was similar to a study done in Chennai by Ravikumar C et al. ${ }^{4}$ Majority of the dentists were using resin based sealers in treatment of vital and non-vital cases because various authors suggested that the resin based sealers have the best apical sealing ability and the best adhesion to obturation materials as well as dentin. ${ }^{7,8,10,11}$

ZOE based sealers have been used in dentistry for many years but were also known for their irritative nature, cellular toxicity and easy solubility in oral fluids. The calcium hydroxide based sealers lead to biological closure of the apical region in a sterile way while Resin based sealers are used in dental practice for their favourable characteristics such as good sealing ability, easiness in mixing, adhesion to dentin and long working time. ${ }^{7,8,9,12,13}$

\section{CONCLUSION}

Obtaining a hermetic seal in root canal is extremely difficult. Root canal obturation is an important determinant in the success or failure of the endodontic treatment. The study enabled us to know the various types of sealers and their sealing efficacy and hence guide us that there is not only one but in clinical practice many of the sealers are used. But commonly used sealers are AH plus followed by ZOE. However, dental researchers are still searching for the ideal root canal filling material, which would have ideal physical, chemical and biological properties as it directly affects the outcome of the endodontic therapy.

\section{REFERENCES}

1. Iqbal A, Iftikhar A, Qureshi B, Sghaireen MG, AL-Omiri MK. A Survey of Standard Protocols for Endodontic Treatment in North of KSA. ISRN Dentist;2014: Article ID 865780.

2. Khalid S, Al-Fouzan. A survey of root canal treatment of molar teeth by general dental practitioners in private practice in Saudi Arabia. The Saudi Dent J 2010;22(3):113-7.

3. Eldeniz AU, Orstavik D. A laboratory assessment of coronal bacterial leakage in root canals filled with new and conventional sealers. Int End J 2009;42:303-12.

4. Ravikumar C, Sharma S. A Survey on the Knowledge of Root Canal Sealers Among 100 Dental Practitioners Endodontists and Pedodontists. Res J Pharm Techno 2017;10(5):133943.

5. Kaur A, Shah N, Logani A, Mishra N. Biotoxicity of commonly used root canal sealers: A metaanalysis. J Conserv Dent 2015; 18:83-8.

6. Faria NB, Massi S, Croti HR, Gutierrez JCR, Dametto FR, Vaz LG. Comparative assessment of the flow rate of root canal sealers. Rev Odonto Ciênc 2010; 25(2):170-3.

7. Filho MT, Maria J, Tanomaru G, Leonardo MR, Silva LAB. Periapical Repair after Root Canal Filling with Different Root Canal Sealers. Braz Dent J 2009;20(5):389-95.

8. Boyadzhieva E, Dimitrova S, Filipov I, Musurlieva N. Survey on Materials, Methods And Difficulties in Obturating the Root Canal System Among Bulgarian Dental Practitioners. J Dent Med Sci 2017 ;16(7): 83-8.

9. Desai S, Chandler N. Calcium Hydroxide -Based Root Canal Sealers: A Review. J Endod 2009;35(4):475-80.

10. Singh H, Markan S, Kaur M,Gupta G. "Endodontic Sealers": Current Concepts and Comparative Analysis. Dent Open J 2015;2(1):32-7. 11. Gatley S, Hayes J, Davies C. Requirements, in terms of root canal treatment, of undergraduates in the European Union: an audit of teaching 
practice. Br Dent J 2009;207(4): 165-170. 12. Gilbert GH, Tilashalski KR, Litaker MS, McNeal SF, Boykin MJ, et al. Outcomes of root canal treatment in Dental Practice-Based Research Network practices. Gen Dent 2010; 58: 28-36.
13. Jenkins SM, Hayes SJ, Dummer PM. A study of endodontic treatment carried out in dental practice within the UK. Int Endo J 2001;34: 16-22.

Source of support: Nil, Conflict of interest: None declared

Cite this article as:

Upadhyay MK, Tyagi KK, Khangura RK. Viewpoints of Dental Practitioners regarding Choice of Root Canal Sealers in Nepal. Int Healthcare Res J 2017;1(8):258-262.

\section{AUTHOR AFFILIATIONS}

Assistant Professor, Department of Conservative Dentistry, MB Kedia Dental College Pvt. Ltd, Birgunj, Nepal

Assistant Professor, Department of Oral and Maxillofacial Pathology, MB Kedia Dental College Pvt. Ltd, Birgunj, Nepal

Reader, Desh Bhagat Dental College and Hospital, Mandi Gobindgarh, Punjab

Corresponding Author:

Dr. Krishan Kumar Tyagi

Assistant Professor

Department of Oral and Maxillofacial Pathology

MB Kedia Dental College Pvt. Ltd

Birgunj, Nepal

+9779816210299

krish.krish621@gmail.com

\section{LEGENDS}

\begin{tabular}{|c|c|}
\hline Characteristics & $\mathbf{N}$ \\
\hline \begin{tabular}{ll}
\multicolumn{2}{l}{ Gender } \\
$-\quad$ & Male \\
- & Female \\
\end{tabular} & $\begin{array}{l}39(34.8 \%) \\
73(65.2 \%)\end{array}$ \\
\hline $\begin{array}{l}\text { Years of experience } \\
\text { (teaching / practicing ) } \\
\text { 1-5 years } \\
\text { 5-10 years } \\
\text { More than } 10 \text { year }\end{array}$ & $\begin{array}{l}42(37.5 \%) \\
30(26.8 \%) \\
40(35 \cdot 7 \%)\end{array}$ \\
\hline $\begin{array}{l}\text { Career prospective } \\
\text { - Academician } \\
\text { - Clinician } \\
\text { - } \text { Both }\end{array}$ & $\begin{array}{l}27(24.1 \%) \\
30(26.8 \%) \\
55(49.1 \%)\end{array}$ \\
\hline
\end{tabular}

Table 1. Demographic characteristic of study participants 


\begin{tabular}{|c|c|c|c|}
\hline S.no & Type of Sealer & Frequency & $\begin{array}{l}\text { p value } \\
\text { (ANOVA) }\end{array}$ \\
\hline 1 & Intrafill & $10(8.9 \%)$ & \\
\hline 2 & AH plus & $24(21.4 \%)$ & \\
\hline 3 & Roeko seal & $5(4.4 \%)$ & \\
\hline 4 & Resilion & $19(16.9 \%)$ & $f=1.747$ \\
\hline 5 & $\mathrm{ZOE}$ & $21(18.7 \%)$ & $.001^{*}$ \\
\hline 6 & Metapex & $17(15.1 \%)$ & (Between Groups) \\
\hline 7 & KetacEndo & $7(6.2 \%)$ & \\
\hline 8 & AR plus & $9(8 \%)$ & \\
\hline
\end{tabular}

Table 2. Respondent's viewpoints regarding root canal sealers 